
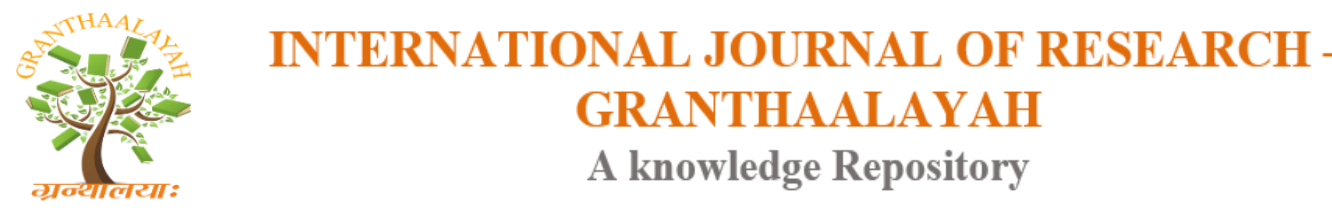

Social

\title{
VALIDITY OF PRIMARY SCHOOL EXAMINATION AS A PREDICTOR OF SECONDARY SCHOOL EXAMINATION SCORE AMONG PUBLIC SECONDARY SCHOOL STUDENTS KENYA
}

\author{
Eunice Atieno Agingu *1 \\ ${ }^{* 1}$ Phd Student, Department of Educational Psychology, School of Education, Jaramogi Oginga \\ Odinga University of Science and Technology (Jooust), Kenya
}

\begin{abstract}
The purpose of this study was to determine the validity of KCPE as a predictor of KCSE scores among public secondary school students in Kisii central Sub-county, Kenya. This study was guided by a conceptual framework where KCPE was the independent variable and KCSE the dependent variable. It adopted Correlational and Ex-post-facto research designs. The study population was 3,897 KCSE candidates from 55 public secondary schools. Stratified random sampling based on school type and size was used to select 16 public secondary schools for the study. Saturated sampling was employed to include all KCSE candidates whose KCPE marks were available in each sampled school, yielding a sample of 1,391 students. Data used included 2006 KCPE scores and 2010 KCSE scores of the same students under study. Data was collected using a researcher made pro forma. It was analyzed quantitatively using correlations and regression analyses. Results showed a strong positive Pearson's correlation coefficient $(r=0.693 ; n=1391 ; p<0.05)$ between $\mathrm{KCPE}$ and KCSE scores. It recommended that; KCPE should continue to be used as selection tool for secondary school admission and school evaluation using KCSE examination scores should be based on students' past KCPE scores.
\end{abstract}

Keywords: Kenya Certificate of Primary Education (KCPE); Kenya Certificate of Secondary Education (KCSE); Predictive Validity: Academic Achievement (Achievement In Standardized Tests).

Cite This Article: Eunice Atieno Agingu. (2018). "VALIDITY OF PRIMARY SCHOOL EXAMINATION AS A PREDICTOR OF SECONDARY SCHOOL EXAMINATION SCORE AMONG PUBLIC SECONDARY SCHOOL STUDENTS KENYA." International Journal of Research - Granthaalayah, 6(4),80-94.https://doi.org/10.29121/granthaalayah.v6.i4.2018.1483

\section{Introduction}

In Kenya, public examinations have been used for decades as a selection instrument for further education and training. The Kenya Certificate of Primary Education (KCPE) is the first of such selection examinations (Othuon \& Kishor, 1994). It is a standardized national examination given 
to pupils at the end of eight years in primary school. At the end of four years in secondary school, students take the Kenya Certificate of Secondary Education (KCSE) examination.

\subsection{Background to the Study}

Success in educational instruction is measured by the performance of students in external examinations. The examinations are used to measure the level of candidates' achievement. For policy makers, examinations are used to evaluate the curriculum implementation. For teachers and students, they are used for promotion to the next level of learning and for certification (Jagero, 2013). Examinations are also used for selection of students to advanced training programs (Masibau \& Adigun, 2010)

In test validity, any device employed by an individual or an examining body for the purpose of selecting candidates for any training program in a given field should be able to measure as accurately as possible the probability that such candidate will pass or fail (Alonge, 1989 as cited in Ugwuda \& Okechukwu, 2013; Masibau \& Adigun,2010). This is to say that success or failure is an effect of the method of selection of candidates for such a training program. This is the core of test validity. Since one important use of KCPE scores is to select learners to various cadres of secondary schools, its predictive validity needed to be clearly known. This was the purpose of this study.

\subsection{Statement of the Problem}

From the reviewed literature it was observed that while some studies report effectiveness of past examination scores in predicting future scores, others differ and suggest that past examination scores are not effective in predicting future scores. On the same note, some separate studies also postulated that some learners score very highly in KCPE but end up failing at KCSE while others improve as yet others maintain.

In the year 2015, the Basic Education Amendment Bill (2014) which sought to scrap the KCPE and KCSE examinations had been tabled in Kenya's Parliament. The amendments in this bill proposed end year progress examinations for pupils in primary and students in secondary schools. The yearly progress examination reports should then be computed and averaged to arrive at the learner's final grade which would be used to ensure pupils go to secondary schools and students proceed to university (Murimi, 2015). This state of affairs was a serious pointer that the law makers in Kenya had begun to doubt the role of KCPE and KCSE as selection tools for placement of learners to the next program of education. An investigation into the predictive validity of KCPE scores for KCSE scores would therefore justify whether this national examination should be scrapped or retained.

Selection of form one students to various cadres of secondary schools is merit-based in such a way that high achieving learners are placed in national and county boarding schools while low achievers are placed in day schools as others fail to secure any place in secondary school at all due to very low KCPE scores. Parents, learners and education stakeholders can always tell whether and where a learner is likely to be admitted for secondary school education based on their KCPE scores. In 2009, Kisii Central had 8,514 KCPE candidates from 261 schools that scored a mean of 
229.34 out of 500 marks. Only $31(0.36 \%)$ were selected to join national schools while 3,060 $(35.9 \%)$ and 3,375 (39.6\%) joined county and sub-county secondary schools respectively as 2,048 $(24.1 \%)$ missed places in secondary schools. When the same cohort sat for Kenya Certificate of Secondary Education (KCSE) in 2013 the sub-county had a mean of 5.1 out of 12 points. Since KCPE examination score is accorded such a central role in selection of learners for secondary school education where it determines their fate with such finality, it was important to verify, through an empirical study, its effectiveness as a selection tool for secondary school education in Kisii Central Sub-County.

\subsection{Literature Review}

According to Hall (2015) whether or not past performance can predict future performance for learners has been a highly debated issue. In a study carried out to examine the validity of secondary school entrance scores in predicting the academic success of secondary school aged students, Hall found a correlation coefficient of $r=0.54, p<0.0005$ between Barbados Secondary School Entrance Examination (BSSEE) and Caribbean Secondary Education Certificate (CSEC). This study suggested that teachers should use students' performance in BSSEE as a diagnostic tool for remediation whereby it would identify the deficiencies students possess at this stage. This knowledge could be employed to inform the development of remedial programs for students who perform poorly on the BSSEE.

The study by Hall (2015) was in agreement with an earlier study by Hattie (2012, as cited in Hall, 2015) who found that prior achievement was a significant contributor to future performance. However, many studies and official reports have pointed to the limitation of public examinations. These include a report given by Kellaghan and Maduas (2003, as cited in Hall, 2015) that suggested a heavy reliance on paper and pencil tests limits the knowledge and skills that can be tested and that exams contain very little reference to the everyday life of the student outside the school. On the same vein, $\mathrm{Wu}$, Huges and Knok (2010) argued that allocation of secondary schools based on a one-off examination does not give everyone taking the exam affair chance to receive maximum results and that there are many factors that prevent exceptional students from performing their best on the examination day. Another study by Obioma and Salau (2007) reported that although high stake examinations were statistically significant, they were found not to be of much practical importance in predicting the achievement of students. The study by Hall (2015) used entry exanimations set by various schools admitting students to secondary schools as the independent variable. It was therefore important to find out the relationship between scores in a standardized past examination (KCPE) and scores in a future examination (KCSE) in Kisii central sub-county in Kenya.

In Nigeria, a study conducted by Ugwuda and Okechukwu (2013) to examine the predictive validity of Nigerian Examination Council (NECO) Junior School Certificate Examination on students' achievement in NECO Senior School Certificate Examination, it was concluded that achievement of students in core subjects at the JSCE could positively predict students' performance at the SSCE. The core subjects in this study were English, Igbo language, Math and Social studies. This study did not include aggregate score of all the subjects offered at each level of examination. Therefore the study conducted in Kisii central sub-county sought to find the predictive validity of aggregate KCPE scores on aggregate KCSE scores. 
In Malawi, the problem of limited places in government secondary schools forces the government to use scores in the Primary School Leaving Certificate Examination (PSLCE) to select learners into the available Form One places in order of merit. With this system, the Ministry of Education ensures that the top performers on the PSLCE are able to attend the top secondary schools (de Hoop, 2010). A study of the 2004 PSLCE candidates admitted in conventional government schools after two years of secondary school in 2006, revealed a strong evidence of the positive impact of selection into a conventional school on the probability of passing the Junior Certificate Examination (JCE). This study however did not give the level of strength of association between PSLCE and JCE examination scores but instead gave the percentages of pupils who passed JCE after being selected to various schools based on their score on PSLCE. It is also noteworthy that in the Malawi study PSLCE and JCE scores were correlated after two years (at the end of Form Two). It would therefore be needful to correlate the scores of learners under study after four years (at the end of Form Four). This would reveal whether the relationship between scores in a past examination would still be strong or weaken if the duration between the two examinations was longer.

In a study conducted in Tanzania to investigate the predictive validity of Form Two Secondary Education Examination (FTSEE) on students' performance in in the Certificate of Secondary Education Examination (CSEE) in Biology Komba, Kafanabo, Tryphone and Kira (2013) found a positive correlation between FTSEE and CSEE. This study did not however include aggregate score of all subjects offered at each level of examination. It covered only one subject, Biology, which could not give a true picture on the predictive validity of the FTSEE examination.

According to Amburo (2011), a study carried out in Nyanza, Rift Valley and Western Kenya found a Pearson's correlation coefficient of $r=0.452, p<.01$ between KCPE raw mark of learners from public primary schools and KCSE raw marks of learners from public secondary schools. The study used purposive sampling technique where six provincial secondary schools were involved. The outcome of this study could be therefore as a result of the fact that samples were drawn from schools with almost similar characteristics. Could the outcome be therefore different if different levels and types of schools were used in a separate study? The study in Kisii Central sub-county set out to answer this question.

In Kenya, an article carried in the QUEST News in March 2008 reported that top students in Grade Eight examinations are likely to perform just as well in secondary examinations. Despite this trend, it went on, statistics however show that some students who excelled in Grade Eight failed to clinch the top 100 slots in the secondary examinations. In the $2007 \mathrm{KCSE}$ results, some students who five years earlier did not perform well emerged among the top 100 nationally. These claims were not backed by results from any empirical study which could have given a true picture of the status.

Another study of the predictive validity of the Kenya Certificate of Primary Education (KCPE) examination was carried out by Othuon and Kishor (1994) to determine the extent to which KCPE predicts success in KCSE found a moderate linear relationship $(r=.56 ; n=781 ; p<0.01)$ between KCPE and KCSE. The predictive validity did not significantly vary from one school to the other. Stratified random sampling technique was used to select 26 secondary schools within a single district, South Nyanza District, in Kenya. The study concluded that KCPE was a moderate predictor of success in secondary school. Since this study was carried out, the KCPE and KCSE 
syllabi have so far changed in terms of number and content of mandatory examinable subjects. According to the Kenya National Examination Council, the 1987 KCPE examination comprised six examinable subjects, namely Mathematics, English, Kiswahili, Science \& Agriculture, Geography, History, Civics \& Religious education, and Art \& Craft, Home science \& Music. In the 2006 KCPE examination, the number of subjects was reduced to five whereby Art \& Craft, Home science \& Music was excluded. Besides, Agriculture was removed from science as an examinable subject. In KCSE 1991, learners were graded for 10 mandatory subjects while in 2010 KCSE a learner required only seven mandatory subjects to be graded. It was therefore necessary to re-examine the predictive validity of KCPE for KCSE after the syllabi revision in order to find out whether syllabi revision made KCPE a better or worse predictor of KCSE, hence the Kisii Central sub-county study.

In a study using regression analysis of entry scores (KCPE) and final scores (KCSE), Ondima, Nyamasege, Mogwambo and Ochoti (2013) postulated that some students who do not score good marks in KCPE pass in KCSE while those who score good marks end up scoring low in KCSE as some maintain. Their study which was carried out in Nyamira sub-county of Nyamira county found a strong positive relationship of Pearson's correlation coefficient $r=.661$ between KCPE and KCSE, scores. Since Kisii Central Sub-county neighbors Nyamira sub-county, it was important to find out if this status was the same or differed especially if a bigger sample size was used given that the Nyamira sub-county study used a sample size of 572 only.

\section{Research Methodology}

\subsection{Research Design}

The study adopted ex-post facto and correlational designs. The ex-post facto design is a nonexperimental research technique in which pre existing groups are compared on some dependent variable. The assignment of participants to the levels of independent variables is based on events that occurred in the past (Lammers \& Badia, 2005). In this study ex-post facto research design was used to retrieve data on $2010 \mathrm{KCSE}$ scores and the corresponding $2006 \mathrm{KCPE}$ scores of the students from the data banks of the sampled schools.

Correlational research design shows relationship between two variables thereby showing a cause and effect relationship (Rippy, 2012). It also shows predictions of future event or outcome from a variable. In this study, Correlational design was used to correlate KCPE and KCSE scores for the students under study where the dependent variable was the KCSE scores and the independent variable was the KCPE scores of the same students sampled for the study.

\subsection{Study Population}

The study comprised 3,897 KCSE candidates of the year 2010 from 55 public secondary schools in Kisii Central Sub-County. 


\subsection{Sampling Technique and Sample Size}

Two sampling techniques were used in this study. The first was stratified random sampling technique which was used to select 16 public secondary schools for the study and thereafter saturated sampling technique was used to select learners from each sampled school.

In this study, the stratification was based on school category and school size whereby the researcher first listed all the 55 schools according to their strata, and selected the required number from each stratum randomly. There were two separate lists based on school category whereby day schools were listed separately from boarding schools. Nine day schools were randomly selected from the list of day schools and six boarding schools were randomly selected from the list of boarding schools for the study. Based on school size three lists were made to include one for large schools, another for medium sized schools and the third for small sized schools. Out of the three lists, four large, five medium sized and seven small schools were randomly selected for the study. It should be noted that school characteristics overlapped in such a way that there were boarding schools that were large, small or medium sized. There were also day schools that were medium or small sized.

From the 16 selected schools, saturated sampling technique was used whereby scores for all KCSE graduates whose KCPE marks were available in each sampled school was used in the study. The sample yielded a total of 1,391 students from 16 secondary schools.

\subsection{Instrumentation and Data Collecting Procedure}

Data was collected from the sampled schools using a researcher-made Pro forma (Appendix B). This contained information on the school name, category and size. The pro forma, which was in form of a table, also included columns of students KCSE index number, gender, KCPE scores and KCSE scores. It was used to record the $2006 \mathrm{KCPE}$ scores and the $2010 \mathrm{KCSE}$ scores of students in the sampled schools.

There were some schools that had analyzed their results on computer and had included a column for the KCPE scores for their students. For such schools, the researcher simply collected a copy of the analyzed result but with the column for students' names excluded for the purpose of confidentiality (See Appendix C). It was occasionally impossible to obtain KCPE scores for students who joined their schools at other levels other than Form One. In such incidences, students whose KCPE marks were missing were not included in the study.

The researcher obtained a permit to carry out the research from the National Council of Social Sciences through Maseno University Ethics Review Committee (MUERC) (See Appendix A). Data was collected from the examination office of each sampled school using the researcher-made Pro forma (See Appendix B).

\subsection{Methods of Data Analysis}

In this study, data analysis was quantitative. The collected data was analyzed using descriptive statistics namely scatter plots and pie charts. Scatterplots indicated whether KCPE and KCSE were 
positively or negatively related. Inferential statistics including correlation and regression analyses were also used. Pearson's product moment correlation coefficients were determined to show the strength of relationship between KCPE and KCSE scores for the subjects in the study. Linear regression analyses were preceded by the necessary regression diagnostics such as violation of normality assumption for the dependent variable, checking outliers and extreme values.

Simple linear regression analysis with KCSE scores as the dependent variable and KCPE scores, as the independent variables was conducted. A linear regression equation was determined which could be used to predict mean KCSE scores from the independent variable (KCPE scores) in the regression model. Regression analysis helped to determine how much of the variance in KCSE scores could be explained by KCPE scores.

\section{Results and Discussion}

\subsection{Introduction}

In this study, the interpretation of the strength of Pearson's Correlation coefficients was given according to general guidelines provided by Cohen (1988). The guideline was given for a sample size $\geq 30$ and significance level of $<0.05$ as follows:

$0.1<|\mathrm{r}|<0.3 \rightarrow$ small/weak correlation $0.3<|\mathrm{r}|<0.5 \rightarrow$ medium/moderate correlation $|\mathrm{r}|>0.5 \rightarrow$ large/strong correlation, where $|\mathrm{r}|$ is the absolute value of the Pearson's correlation coefficient $r$, regardless of whether it is positive or negative.

\subsection{Relationship Between Learners' KCSE And KCPE Scores}

In order to determine the relationship between KCPE and KCSE scores for the learners, a scatterplot for KCSE against KCPE was generated as shown in Figure 1.

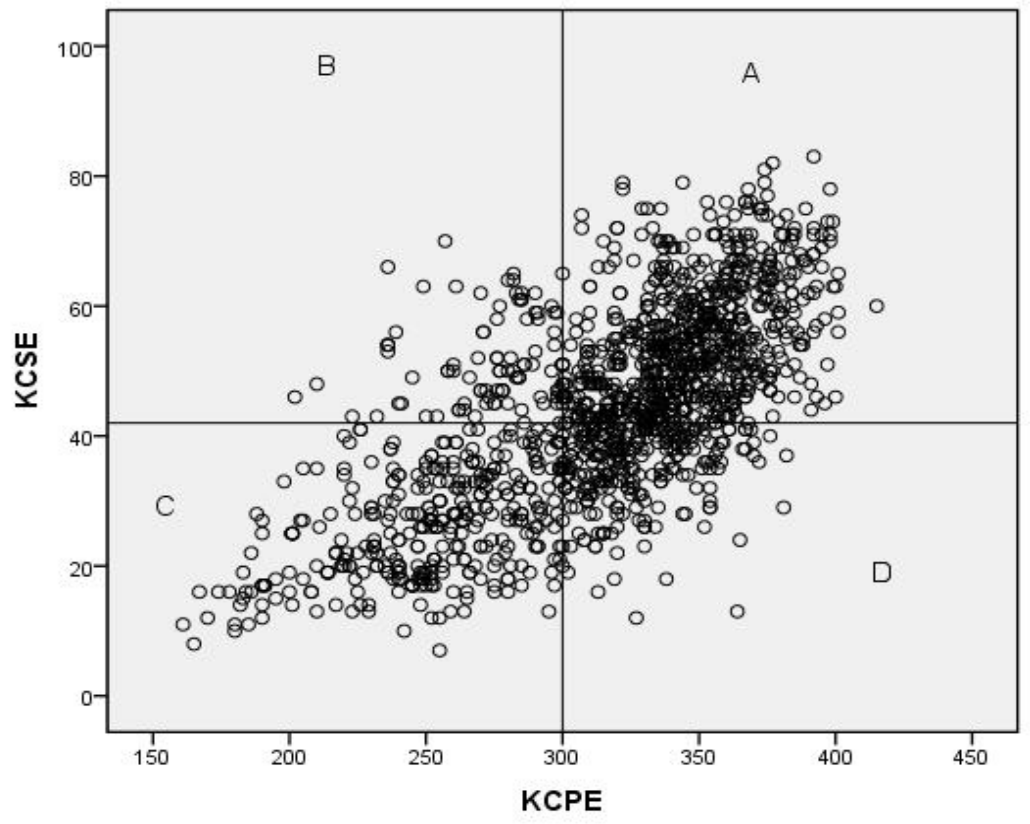

Figure 1: Bivariate Scatterplot of KCSE against KCPE scores 
Note. Independent variable: $\mathrm{KCPE}$

Dependent variable: KCSE

Source: Field data

The scatterplot illustrated in Figure 1 shows the scatter points concentrated along the diagonal towards the right indicating that there was a positive linear relationship between KCPE and KCSE scores for the sampled learners. The scatterplot was further divided into four quadrants, A, B, C and D. Quadrant A represents learners who had high KCPE scores (300 marks and above) and also ended up getting high KCSE scores (42 points and above). Quadrant B represents learners who had low KCPE scores but ended up scoring highly in KCSE. Data points in quadrant C represent learners who had low KCPE scores and also ended up getting low KCSE scores. Quadrant D represents learners admitted to secondary schools with high KCPE scores but ended up recording low KCSE scores.

In order to get more details on the relationship between the KCSE and KCPE scores, Pearson's correlation coefficient test was carried out on the sample and the result given in Table 1.

Table 1: Pearson's Correlations Coefficient between KCSE and KCPE scores

**. Correlation is significant at the 0.01 level (2-tailed).

\begin{tabular}{|l|l|l|l|}
\hline & & KCPE & KCSE \\
\hline \multirow{3}{*}{ KCPE } & Pearson Correlation & 1 & $\mathbf{. 6 9 3}^{* *}$ \\
\cline { 2 - 4 } & Sig. (2-tailed) & & .000 \\
\cline { 2 - 4 } & N & 1391 & 1391 \\
\hline \multirow{2}{*}{ KCSE } & Pearson Correlation & $\mathbf{. 6 9 3}^{\text {** }}$ & 1 \\
\cline { 2 - 4 } & Sig. (2-tailed) & .000 & \\
\cline { 2 - 4 } & N & 1391 & 1391 \\
\hline
\end{tabular}

Source: Field data

As can be observed from Table 1, the correlation between KCPE and KCSE scores yielded a Pearson's correlation coefficient $r=.693 ; n=1391 ; p<0.05$ between the two variables in a two-tailed test. According to Lund and Lund (2014), the magnitude of the Pearson's Correlation Coefficient determines the strength of the correlation. Although there are no hard- and-fast rules for assigning strength of association to particular values, general guidelines provided by Cohen (1988) were used. Therefore, in this study, the Pearson's correlation coefficient of $r=.693$ observed in Table 1 can be described as a strong positive relationship. This means there is a strong positive correlation between KCSE and KCPE scores, suggesting that students who score highly at KCPE are also likely to score highly at KCSE and vice versa.

Further investigation on the relationship between KCSE and KCPE scores for the sample was done using regression analysis and the result given in Table 2. 
Table 2: Regression Analysis of KCSE scores on KCPE scores

\begin{tabular}{|c|c|c|c|c|c|c|}
\hline Model & $\mathbf{R}$ & $\mathbf{R}^{2}$ & $\begin{array}{l}\text { Adjusted } \\
\mathbf{R}^{2}\end{array}$ & $\begin{array}{l}\text { Standard } \\
\text { Error } \\
\text { estimated }\end{array}$ & \multicolumn{2}{|l|}{$\mathbf{F}$} \\
\hline 1 & ${ }^{\mathrm{a}} .693$ & .481 & .480 & 10.964 & \multicolumn{2}{|l|}{1286.341} \\
\hline Model & \multicolumn{2}{|c|}{$\begin{array}{l}\text { Unstandardized } \\
\text { beta }\end{array}$} & $\begin{array}{l}\text { Coefficient } \\
\text { Standard } \\
\text { error }\end{array}$ & $\begin{array}{l}\text { Standardized } \\
\text { beta }\end{array}$ & $\mathrm{t}$ & Sig \\
\hline 1 (constant) & \multicolumn{2}{|c|}{-24.616} & 1.934 & \multirow[t]{2}{*}{.693} & -12.732 & .000 \\
\hline KCPE & \multicolumn{2}{|c|}{.218} & 0.006 & & 35.866 & .000 \\
\hline
\end{tabular}

Confidence interval $(\mathrm{CI})=95 \%$

$\mathrm{N}=1391$

Total df. $=1390$

a. predictor KCPE

Source: Field data

Table 2 displays the result of simple linear regression of KCSE scores on KCPE scores. The regression result was $\mathrm{R}^{2}=.481, \mathrm{~F}(1,1390)=1286.34, \mathrm{p}<0.05$. This implied that $48.1 \%$ of the variance in KCSE scores could be explained by the score in KCPE. This is a high percentage which explains that KCSE scores has a high correlation with KCPE scores. The remaining 51.9\% variance in KCSE scores can be explained by other factors other than KCPE scores.

From the regression analysis shown in Table 2, the unstandardized beta when KCSE scores was regressed against KCPE scores was 0.218 . The $t$ value was 35.866 and its significance was .000 (less than the critical .05 level). This shows that KCPE scores had a major impact on KCSE scores. The unstandardized beta value of 0.218 was interpreted to mean that one unit increase in the students' KCPE scores would improve their KCSE scores by 0.218 units. The constant -24.619 was used to formulate a regression equation given as $y=.218 x-24.619$, where $y$ is the KCSE scores and $x$ is the KCPE scores, which may be used to predict the KCSE scores of learners from their KCPE scores if the circumstances are similar to those found in the area of this study.

The finding of this study was in agreement with a similar study carried out by Othuon and Kishor (1994) which found a moderate positive correlation ( $\mathrm{r}=.56$; $\mathrm{n}=781 ; \mathrm{p}<0.01)$ between KCPE and KCSE scores of the learners sampled in South Nyanza District. A similar study conducted by Ondima, Nyamasege, Mogwambo and Ochoti (2013) in Nyamira Sub-County of Nyamira County found a strong positive correlation ( $r=0.661 ; n=572 ; \mathrm{p}<0.001$ ) between KCPE and KCSE scores for the learners under study. Jagero (2013) in a study conducted in a private school in Western Kenya similarly found a positive correlation $(\mathrm{r}=0.599 ; \mathrm{n}=110 ; \mathrm{p}<0.01)$ between KCPE and KCSE in a two tailed test. Another study conducted by Amburo (2011) found a slightly lower but positive relationship $(r=0.452 ; n=240 ; p<0.01)$ between KCPE and KCSE scores of learners from public primary schools admitted to provincial public secondary schools. Therefore, learners who attain high scores in KCPE examinations are also likely to attain high scores in KCSE examinations and those who score low marks on KCPE are also likely to score low marks on KCSE.

The Correlation Coefficient of $\mathrm{r}=0.693 ; \mathrm{n}=1391 ; \mathrm{p}<0.05$ in the Kisii Central study was higher than 0.56, 0.661 and 0.599 quoted in the previous studies (Amburo, 2011; Jagero, 2013; Ondima, 
Nyamasege, Mogwambo \& Ochoti. 2013; Othuon \& Kishor, 1994). Given that the three studies reported above all had smaller sample sizes, the study in Kisii Central sub-County showed a stronger relationship between KCPE and KCSE scores compared to the earlier studies. This suggests that, to some extent, other factors apart from KCPE scores that may affect KCSE scores were fewer in the study area compared to the previously stated studies. This could be due to the fact that in Kisii Central sub-County, there are fewer cases of learners getting involved in distracting activities which may interfere with their learning, making their examination scores more consistent from primary to secondary school and hence the stronger relationship between their KCPE and KCSE scores.

The strong correlation between KCSE and KCPE scores for learners in this study pointed to the fact that learning in primary school impacts on learning in secondary school. As reported by Wanjohi and Yara (2011), some of the learning problems experienced by students in secondary schools have their origin in primary schools.

\section{Conclusions and Recommendations}

\subsection{Conclusion}

$\mathrm{KCPE}$ examination score is a strong predictor of KCSE examination scores. It is therefore possible to predict the future KCSE scores from learners' KCPE scores in public secondary schools in Kisii Central Sub-County.

\subsection{Recommendations of the Study}

From the findings of this study the researcher has made the following recommendations; The KCPE examination score should continue to be used as a selection tool for enrolment of learners into secondary schools as those who score highly in the KCPE examination are also likely to score highly in the KCSE examination.

Evaluation of schools based on KCSE scores should take into account the mean KCPE scores of learners in those schools. This can be achieved by comparing a school's actual mean KCSE scores with the predicted KCSE scores computed from the learners' mean KCPE scores, rather than the current blanket evaluation of schools which is unfair to schools admitting learners with low KCPE marks.

\section{Acknowledgements}

This study was supported by Maseno University, Kenya. I specially thank Prof John Agak and Prof Lucas Othuon from the Department of Educational Psychology, School of Education for their professional support. 


\title{
Appendixes
}

Appendix A: Research Approval from Maseno University Ethics Review Committee

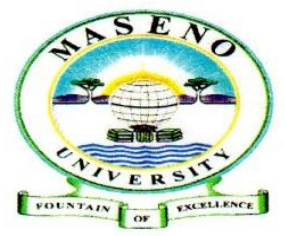

\section{MASENO UNIVERSITY ETHICS REVIEW COMMITTEE}

Tel: +254057351622 Ext: 3050

Fax: +254057351221
Private Bag - 40105, Maseno, Kenya Email: muerc-secretariate@maseno.ac.ke

DATE: $31^{\text {St }}$ March, 2014

REF: MSU/DRPC/MUERC/000061/14

TO:

Eunice Atieno Agingu, PG/MED/00020/2009,

Department of Education Psychology,

School of Education, Maseno University, Private Bag, Maseno, Kenya

\begin{abstract}
RE: Validity of Certificate of Primary Education Examination Score as a Predictor of Certificate of Secondary Education Examination Score in Public Secondary Schools in Kisii Central District, Kenya. PROPOSAL REFERENCE NO: MSU/DRPC/MUERC/000061/14
\end{abstract}

This is to inform you that the Maseno University Ethics Review Committee (MUERC) determined that the ethics were adequately addressed in the submitted proposal. Consequently, the study is granted approval for implementation effective this $31^{\text {st }}$ day of March, 2014 for a period of one (1) year.

Please note that authorization to conduct this study will automatically expire on $30^{\text {th }}$ March, 2015. If you plan to continue with the study beyond this date, please submit an application for continuation approval to MUERC Secretariat by $28^{\text {th }}$ February, 2015.

Approval for continuation of the study will be subject to successful submission of an annual progress report that is to reach MUERC Secretariat by $28^{\text {th }}$ February, 2015.

Please note that any unanticipated problems resulting from the conduct of this study must be reported to MUERC. You are required to submit any proposed changes to this study to MUERC for review and approval prior to initiation. Please advice MUERC when the study is completed or discontinued.

Thank you.
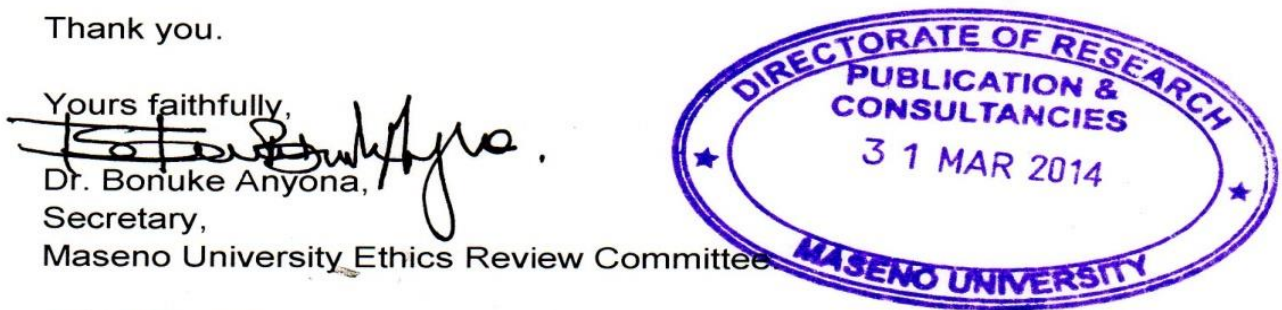

Cc: Chairman,

Maseno University Ethics Review Committee.

$$
\text { MASENO UNIVERSITY IS ISO 9001:2008 CERTIFIED }
$$


Appendix B: Manual Data Collecting Profoma

\begin{tabular}{|c|c|c|c|}
\hline $\begin{array}{l}\text { NAME OF SCHO } \\
\text { NO OF } 2010 \mathrm{KCS} \\
\end{array}$ & 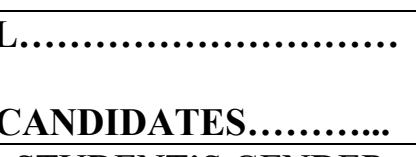 & $\begin{array}{l}\text { CATEGORY: } \\
\text { SIZE: (LARG) }\end{array}$ & $\begin{array}{l}\text { Y, BOARDING) } \\
\text { (EDIUM, SMALL) }\end{array}$ \\
\hline KCSE INDEX NO. & STUDENT'S GENDER & KCPE SCORE & KCSE SCORE \\
\hline & & & \\
\hline & & & \\
\hline & & & \\
\hline & & & \\
\hline & & & \\
\hline & & & \\
\hline & & & \\
\hline & & & \\
\hline & & & \\
\hline & & & \\
\hline & & & \\
\hline & & & \\
\hline & & & \\
\hline & & & \\
\hline & & & \\
\hline & & & \\
\hline & & & \\
\hline & & & \\
\hline & & & \\
\hline & & & \\
\hline & & & \\
\hline & & & \\
\hline & & & \\
\hline & & & \\
\hline & & & \\
\hline
\end{tabular}


Appendix C: Computer generated data from sampled school
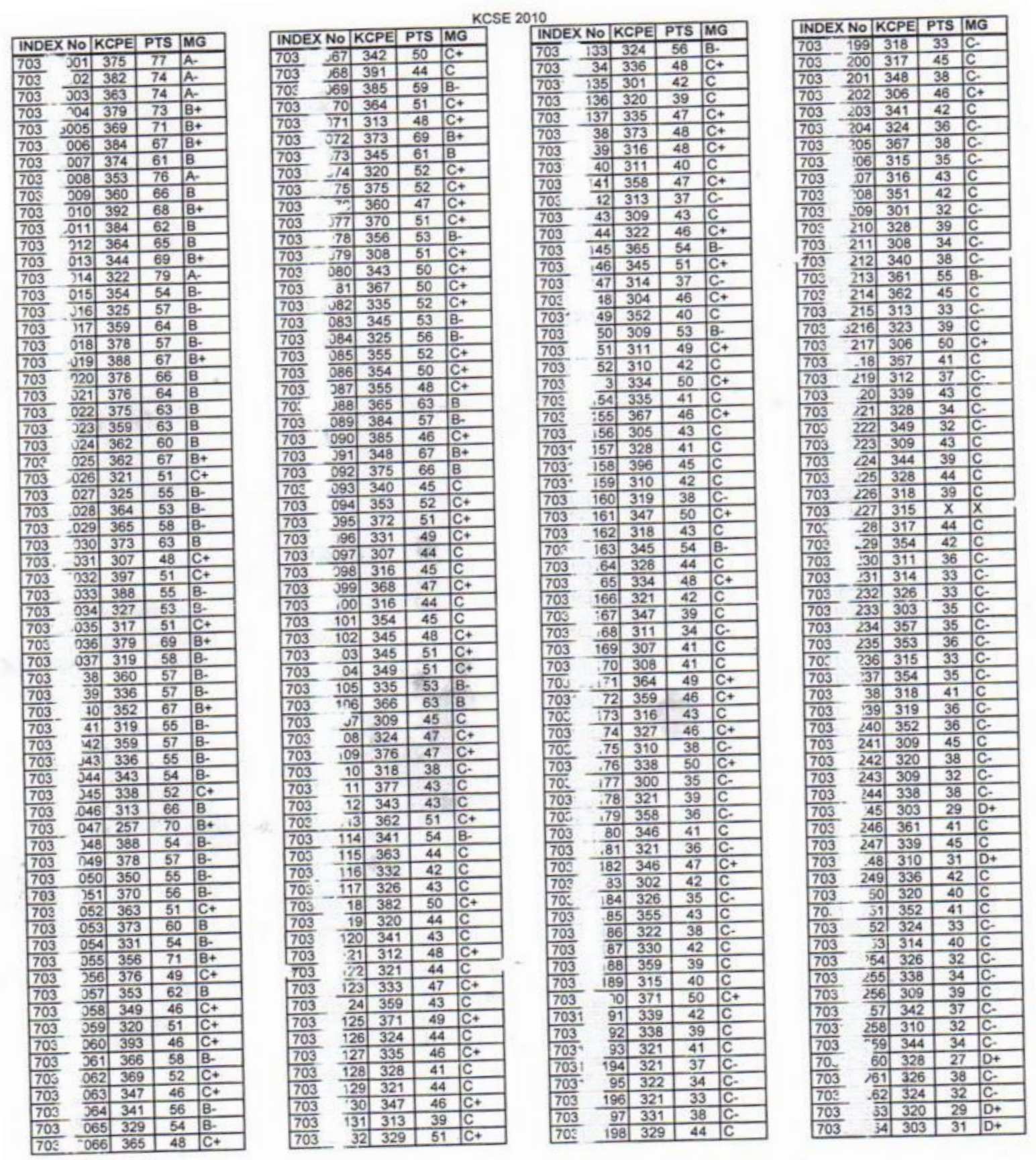

NOTE: The middle figures of the index numbers were concealed to maintain confidentiality. 


\section{References}

[1] Amburo, A.P. (2011). "TEACHING IN A CHANGING AFRICA: DIFFERENTIAL ACADEMIC PERFORMANCE OF STUDENTS FROM ACADEMIES AND PUBLIC PRIMARY SCHOOLS AT KCSE EXAMINATION IN KENYA." International Journal of Innovative and Interdisciplinary Research, 1, 68-73

[2] Cohen, J. (1988). STATISTICAL POWER ANALYSIS FOR THE BEHAVIORAL SCIENCES (2nd ed.). Hillside, NJ: Lawrews Eribaum Associates

[3] de Hoop, J. (2010). "SELECTIVE SECONDARY EDUCATION AND SCHOOL PARTICIPATION IN SUB- SAHARAN AFRICA: EVIDENCE FROM MALAWI". Tinbergen Institute Discussion Paper, 27, 557-577.www.cerdi.org/../deHoop.pdf

[4] Hall, M. T. (2015). “AN EXAMINATION INTO THE VALIDITY OF SECONDARY SCHOOL ENTRANCE SCORES IN PREDICTING THE ACADEMIC SUCCESS OF SECONDARY AGED STUDENTS." Current issues in education, 18(1). http://cie.asu.edu/ojs/index.php/cieatasu/article/view/1343

[5] Jagero, N.O. (2013): "HOW PERFORMANCE OF STUDENTS IN KENYA CERTIFICATE OF PRIMARY EDUCATION CAN PREDICT THEIR PERFORMANCE IN KENYA CERTIFICATE OF SECONDARY EDUCATION." Educational Research International, 1(3), 1119. www.print.savap.org.pk

[6] KCSE Schools Ranking for Kisii Central Sub-County (2010). "KCSE SUB-COUNTY PERFORMANCE SUMMARY-KISII CENTRAL." Kisii Sub-County Education office- Statistics Section.

[7] KCSE Schools Ranking for Kisii Central Sub-County (2011). "KCSE SUB-COUNTY PERFORMANCE SUMMARY- KISII CENTRAL". Kisii Sub-County Education office- Statistics Section

[8] Komba, S. C., Kafanabo, E. J., Tryphone, D. \& Kira, E. S. (2013). "THE PREDICTIVE VALIDITY OF FORM TWO SECONDARY EDUCATION EXAMINATION (FTSEE) ON STUDENTS' PERFORMANCE IN THE CERTIFICATE OF SECONDARY EDUCATION EXAMINATION (CSEE) IN BIOLOGY SUBJECT: A TANZANIAN PERSPECTIVE.” Journal of Education and Practice, 4(4), 236-246. www.iiste.org.

[9] Lammers, W. T. \& Badia, P. (2005). "FUNDAMENTALS OF BEHAVIORAL RESEARCH." California: Thomson Wadsworth. www.reference.com/motif/science/exe....

[10] Lund, A. \& Lund, M. (2014). "CORRELATION AND REGRESSION ANALYSIS IN STATISTICS.” http://statistics.laerd.com/spss

[11] Masibau, A. Y. \& Adigun, J. T. (2010): "THE INFLUENCE OF SCHOOL SEX, LOCATION AND TYPE ON STUDENTS' ACADEMIC PERFORMANCE.” International Journal of Educational Science 2(2): 81-85.www.krepublishers.com/02-Journals.

[12] Murimi, M. (2015, August 6). "BILL SEEKING TO ABOLISH KCPE, KCSE IN PARLIAMENT." Citizen Digital. citizentv.co.ke/news

[13] Obioma, G. \& Salau, M. (2007). "THE PREDICTIVE VALIDITY OF PUBLIC EXAMINATIONS: A CASE STUDY OF NIGERIA. NIGERIAN EDUCATIONAL RESEARCH AND DEVELOPMENT COUNCIL (NERDC). ABUJA. NIGERIA." www.iaea.info/documents/paper_1162d3940.pdf

[14] Ondima, C. M., Nyamasege, D., Mogwambo, B. A. \& Ochoti G. N. A. (2013): "REGRESSION ANALYSIS OF ENTRY SCORES (KCPE) AND FINAL PERFORMANCE (KCSE) IN KENYA: A CASE OF NYAMIRA DISTRICT, NYAMIRA COUNTY, KENYA.” Mathematical Theory and Modelling 3(4) 7-18. International Institute of Science, Technology and Education. www.iite.org

[15] Othuon, L. \& Kishor, N. (1994). "HIERARCHICAL LINEAR MODELLING OF PREDICTIVE VALIDITY: THE CASE OF KENYA CERTIFICATE OF PRIMARY EDUCATION EXAMINATION." Studies in Educational Evaluation 20 pp 175-194. The University of British Columbia, Vancouver, Canada. 
[16] Rippy, M. (2012). "RESEARCH DESIGNS: CORRELATIONAL” education.astate.edu.

[17] Ugwuda, S. O. \& Okechukwu, S. A. (2013). "PREDICTIVE VALIDITY OF NECO JUNIOR SCHOOL CERTIFICATE EXAMINATION ON STUDENTS' ACHIEVEMENT IN NECO SENIOR SCHOOL CERTIFICATE EXAMINATION.” Research gate. researchgate>publication. doi:259761311

[18] Wanjohi, C. W. \& Yara, O. P. (2011). "PERFORMANCE DETERMINANTS OF KCSE IN MATHEMATICS OF SECONDARY SCHOOLS IN NYAMAIYA DIVISION, KENYA.” Asia Social Science, (7), 2107-2112.

*Corresponding author.

E-mail address: agingueunice@ rocketmail.com 